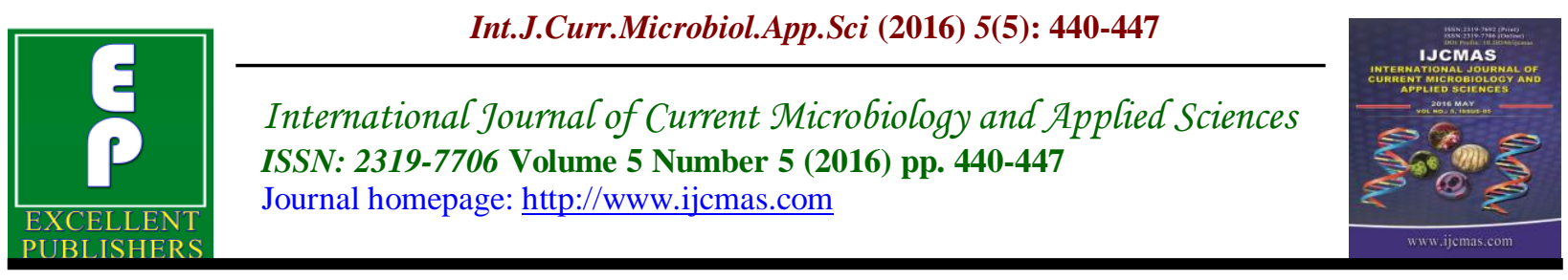

Original Research Article

http://dx.doi.org/10.20546/ijcmas.2016.505.046

\title{
Sterility Testing of Operation Theatres in Hospitals
}

\author{
Abhishek K. Mishra* and Vijay S. Wadhai \\ Centre for Higher Learning and Research in Microbiology, \\ Sardar Patel Mahavidyalaya, Chandrapur, India \\ *Corresponding author
}

A B S T R A C T

\section{Keywords}

Sterility Testing, Operation Theatres, Coagulase negative Staphyloccoci spp.

\section{Article Info}

Accepted:

18April 2016

Available Online:

10 May 2016
This paper describes the presence and type of bacterial contamination in an operation theatres that contributes to the major outbreak of nosocomial infections of Various Hospitals of Wardha city (M.S), India. Samples were collected by open plate method and swab method for air, surface and articles, and were further isolated and identified. The bacterial pathogens comprising of Staphylococcus spp., Pseudomonas spp., and Coagulase negative Staphyloccoci spp were found. High bacterial contamination was observed in air samples taken from operation theaters.

\section{Introduction}

The utility or microbiology within the discipline of drugs has performed a main function within the prevention, remedy and prognosis or illnesses. Most of the microorganism is free dwelling and harmless to people. Certainly maximum of them lead a beneficial existence with people. Transmission of an infectious disease may occur via one or more of numerous pathways along with physical contact with infected people, those infecting retailers are also transmitted thru beverages, meals, airborne inhalation, and via vector-borne spread (David, et al., 2013).

Hospitals are the primary facilities for the remedy of numerous illnesses. In recent times a hospitals itself turns into infected with numerous pathogenic microbial flora.
Due to this patient which might be admitted to the Hospitals cannot get cared as a substitute attained numerous different sort of contamination that's called as medical institution acquired contamination or nosocomial infection (Boyce et al., 2002)

Nosocomial infection is a main hassle in any healthcare facility. Often nosocomial infections become apparent while the affected person continues to be inside the health facility but in some instances symptoms might not show up until after the affected person is discharged. About $30 \%$ of sufferers admitted to hospitals \& nursing houses in our country acquire nosocomial infections as in opposition to an impressive $5 \%$ in the west, in line with members of 
hospital contamination Society (HIS), India. This alarming scenario is attributed to hospitals reluctance to put money into contamination control, lack of information $\&$ mistaken waste control.

Sanatorium acquired infections (health center received infections) are infections acquired in medical institution by way of a patient who was admitted for a reason apart from that infection (WHO, 2000). Hospital obtained infections are one of the vital public fitness issues in many countries throughout the world. A WHO examine, have also shown that the best occurrence of nosocomial infections occurs in intensive care devices and in acute surgical and orthopedic wards (WHO; 2001). Medical institution received infections results in higher morbidity, mortality, and further fees. It's miles well recognized that the danger of transmission of pathogens whilst imparting medical care and the incidence of clinic obtained infections can be kept low through appropriate standardized prevention processes. But, it's been well documented that the extent of compliance with using validated HAI measures by healthcare employees (HCWs) has been disappointing (WHO, 2009). So as to overcome this hassle it is essential to implement and practice prevention and manage techniques with tested fee constantly and carefully. Many of the distinctive techniques, the adherence to pointers for disinfection are a crucial aspect for sports aimed at preventing the health facility obtained infections.

\section{Source of Transmission}

It's far validated that most of the people, as plenty as $80 \%$ of nosocomial infections are due to the microbial life that sufferers deliver with them upon admission to the medical institution. This "live-at-home" vegetation appears to be opportunistic to the new surroundings and is able to take gain of new routes that medical tactics offer. Different nosocomial infections, i.e. around $20 \%$, develop following contamination with microbial organisms found in the medical institution surroundings. The various critical and common mode of infection may be categorized as contact transmission, Droplet Transmission, Airborne Transmission and Vector borne transmission. The superiority of clinic received infections is high in intensive care unit and operation theaters because of patient and environmental elements (William A, 2008). The sufferers are significantly ill and normally immune compromised which predispose them to accumulate infections greater effortlessly. Seriously sick sufferers requiring urgent and emergency interventions in ICU may motive problems to the fitness care workers to have interaction in endorsed hand hygiene practices. There are numerous hints posted with the aid of both international and local businesses together with WHO, CDCD and the Sri Lankan university of microbiologists (Gunasekara, et al., 2009) accessible hygiene. It's very important to carry out regular training applications and surveys to assess the hygiene practices a number of the health care employees in Sri Lanka, particularly within the in depth care units to be able to put into effect contamination manage measures. In Asia there may be a paucity of studies (Patarakul et al., 2005) exploring this subject, although the superiority of health care associated infections is excessive on this place; specially clinical and nursing student's understanding of fashionable precautions is not often as compared (Kim et al., 2001). The observance of hygiene by students is said as being vulnerable (Feather et al., 2000). Therefore, it is clearly vital to analyze and understand nurse's understanding, attitudes, and practices approximately hand hygiene so that suitable 
techniques can be evolved to maintain hygenicity.

\section{Operation Theatre}

Operation Theatres are the unit of hospitals in which surgical procedures are done on patients which can be admitted to hospitals. Surgical procedures are part of medical treatment that calls for very sterile ecosystem round there. Generally we see health center surroundings is complete of contamination i.e. illnesses that is added by way of sufferers inside the hospitals is spreaded over the sanatorium virtually with the aid of its ordinary behavior for e.g. by using sneezing coughing, speaking and touching. They make contributions to the air microbial plants that's dangerous to different and therefore on this manner environment of hospitals turns into the supply of contamination in large part in the ones regions of clinic in which right disinfecting practices are not applied. (Patwardhan, et al., 2011).Operating theatre is likewise lying beneath the medical institution since it has crucial function in the health facility. An operating room includes devices that are crucial for surgical procedure. An operation room has its personal infrastructure special from different devices of hospitals it consists of bed, Lamp, Anesthesia machine, surgical trolley, stool, sterile air system each of which has an critical function in completing the surgical treatment (Javed, et al., 2008)

\section{Microorganisms found in Operation Theater}

Escherichia coli is present everywhere so it may be found in O.T. if not sterilized properly. Actually E.coli is not harmful organism but it sometimes takes action as it is opportunistic organism. Staphylococcus aureus is the main organisms that are usually found in the hospital area (Dharan S, et al., 2005). It is mainly present in the called as staphylococcal diseases. Other types of bacteria's are also found in the hospital area such as Cl.tetani Pseudomonas aeruginosa, S. epiderrnidis, Micrococcus lutes etc (Ensayel, et al., 2009)

The aim and objectives of this study includes, Surgeries are made in the O.T in which there is strictly incision of part of body with respect to disease or disorder i.e. knee joint replacement, cardiac operation, eye operation in such cases if the environment itself contaminated then there are more chances of that patient to become infected by it.

Therefore the following research emphasized on

1. Determining the sterility or O.T.

2. Cautioning to the Hospital Directors, Medical workers, Doctors and staff in OT.

3. It also alerts the patients from becoming infected in hospital.

Birmingham medical institution had proven that Clostridium welchi may be isolated from the air at most times, and that those organisms are apparently carried into the clinic with outdoor air (EJ.L Lowbury et al., 1958). St. Mary's hospital scientific college London published paper on, 'Prevention of contamination in operating theaters." in this paper they showed that there are likely greater chances of staphylococcal infection, clostridial contamination, and infection of the urinary tract with miscellaneous micro organism (Shooter et al., 1996). In line with the look at, infection in operating theatre is a main cause of nosocomial Infection. In a study, 1216 swabs have been accumulated from surfaces, requirement and antiseptic solutions bottles from different operation theaters in $2001 \& 2002$ the rates of positive cultures were $3.7 \%$ in 2001 and $4 \%$ in 
2002. Staphylococcus epidermidis became the maximum commonplace isolate in 2001 followed by Pseudomonas aeruginosa, whereas in 2002 Coliform micro organism had been the best thriving infectious agents followed by $P$. aeruginosa (Ensayef et al., 2009).

The studies performed via Tharnar university college of clinical science on bacterial infection inside the health center and its competitive behaviors it turned into observation that from 50 swabs gathered from gadgets, equipments, devices and affected person touch matters from exceptional medical institution department in 2009 , the rate of positive cultures is 38.2 $\%$, the coagulase -ve Staphylococcus changed into the most commonplace isolated $38.1 \%$ while the Escherichia coli $14.3 \%$.Gram -ve bacteria were found to be the essential infectious agents in second level with $23.9 \%$. No clean pattern become determined in exclusive medical institution theaters. except the splinting (Orthopedic) theater.

Studies accomplished in Hospitals of Akola Maharashtra (India), Isolated and diagnosed the pathogens from medical institution air. Health center air is sampled by exposing the special medium plates to air. 20 samples of air had been analyzed and 50 clinical isolates had been obtained amongst which Staphylococcus aureus, Pseudomonas aeruginosa were observed.

All isolates were subjected to antibiotic sensitivity take a look at via the use of disc diffusion method using multidisc of different antibiotics. Pseudomonas and S.aureus shows resistance to various antibiotics. Indoor air in health center suggests highest contamination. The important position of Aeruginosa in health facility infection is due to its resistance to not unusual antibiotics (Nanoty et al., 2003).

\section{Materials and Methods}

\section{Sample Collection}

The samples were collected from different types of health care center in Wardha City. Specifically the samples were collected from operation theatre of health care center such as General Hospital Children's Maternity home, Dental clinic, Eye care, Cardiac care Skin care, E.N.T, Gynecology cure and Orthopedic clinic. Settle Plate /Open air Method and swab technique was used for enumeration of microorganisms from operation theater.

\section{Inoculation of this sample on CLED agar plate and PDA and RCMM Medium}

Samples are taken from each O.T in such a way that sampling is made in 2 ways i.e. before sterilization and after sterilization.

Potato dextrose Agar plates and CLED agar plates were prepare and are kept open for few minutes in O.T. in order to acquire aerobic microbial flora, and important sites swabs in OT were sampled with the help of swab technique. Swabs were taken from Floor, Bed, Lamp, Wall, and surgical trolley in Operation Theater and were inoculated in RCMM broth. The CLED agar and PDA agar plates and swabs were incubated. The CLED agar and PDA agar plates were incubated at 37 degree $C$ for $24 \& 48$ hours respectively. The swabs were incubated at 30 0C for 2-6 Days. The plates were examined for colony formed. The isolated colonies were identified by using standard procedure.

Performing the Gram staining of isolated colonies of respective medium. And Biochemical Test of the same. 


\section{Results and Discussion}

It was found to be presences of infection causing microorganisms are present in the non-sterilized operation theater in the hospitals. Only the Eye care hospital was found to be free from infecting organisms as compared to other faculty hospitals. It shows that the there is absolute requirement of sterilization which should be done properly.

Table 2 shows that the microorganisms can be eliminated from the operation theater if the proper standard sterilization procedure has been followed throughout. As compared to table 1results in table 2 i.e. after sterilization of operation theater, shows that the operation theater does not have any of the infectious microbes that can cause the infections to the patients.

From these mixed culture single colony were taken for identification of this colonies gram staining were performed. It was observed that:-

Colony Characteristic for the Staphylococcus aureus were gram positive grapes like cluster appearance Deep yellow colour colonies, uniform in colour circular. Pseudomonas aeruginosa were gram negative bacilli short rod shaped Green colour colonies with rough periphery. Clostridium tetani were gram positive, slender bacillus with rounded ends, and some what "drumstick", like appearance

Table.1 Table showing the results from various non- sterilized operation theater site in different type of hospitals

\begin{tabular}{|c|c|c|c|c|c|c|c|c|c|c|}
\hline \multirow[b]{2}{*}{ Sr.No } & \multirow{2}{*}{$\begin{array}{c}\text { Types of } \\
\text { Hospital } \\
\text { O.T }\end{array}$} & \multicolumn{6}{|c|}{ Sampled Sites } & \multirow{2}{*}{$\begin{array}{c}\text { Aerobi } \\
\text { c Flora } \\
\text { on } \\
\text { CLED }\end{array}$} & \multirow{2}{*}{$\begin{array}{c}\text { Anaerobi } \\
\text { c Flora } \\
\text { on } \\
\text { RCMM }\end{array}$} & \multirow{2}{*}{$\begin{array}{c}\text { Funga } \\
\text { l } \\
\text { Flora } \\
\text { on } \\
\text { PDA }\end{array}$} \\
\hline & & Lamp & Bed & Floor & Walls & Trolley & $\begin{array}{c}\text { Anesthesia } \\
\text { Machine }\end{array}$ & & & \\
\hline 1 & $\begin{array}{c}\text { General } \\
\text { Hospital } \\
\end{array}$ & + & + & + & + & + & + & + & + & + \\
\hline 2 & $\begin{array}{l}\text { Children } \\
\text { and } \\
\text { Maternity } \\
\text { Home }\end{array}$ & + & + & + & + & + & + & + & + & + \\
\hline 3 & Eye Care & -- & + & -- & -- & -- & -- & -- & -- & -- \\
\hline 4 & ENT & + & + & + & + & + & -- & + & + & + \\
\hline 5 & $\begin{array}{l}\text { Dental } \\
\text { Clinics }\end{array}$ & + & + & + & + & + & + & + & + & + \\
\hline 6 & Skin Care & -- & + & + & + & + & + & + & + & + \\
\hline 7 & $\begin{array}{c}\text { Cardiac } \\
\text { Care }\end{array}$ & + & + & + & + & + & + & + & + & + \\
\hline 8 & Orthopedic & + & + & + & + & + & + & + & + & + \\
\hline 9 & $\begin{array}{c}\text { Gynaec } \\
\text { Care } \\
\end{array}$ & + & + & + & + & + & + & + & + & + \\
\hline
\end{tabular}


Table. 2 Table showing the results from sterilized operation theater site in different type of hospitals

\begin{tabular}{|c|c|c|c|c|c|c|c|c|c|c|}
\hline \multirow[b]{2}{*}{ Sr.No } & \multirow{2}{*}{$\begin{array}{c}\text { Types of } \\
\text { Hospital } \\
\text { O.T }\end{array}$} & \multicolumn{6}{|c|}{ Sampled Sites } & \multirow{2}{*}{$\begin{array}{c}\text { Aerobic } \\
\text { Flora } \\
\text { on } \\
\text { CLED }\end{array}$} & \multirow{2}{*}{$\begin{array}{c}\text { Anaerobic } \\
\text { Flora on } \\
\text { RCMM }\end{array}$} & \multirow{2}{*}{$\begin{array}{c}\text { Fungal } \\
\text { Flora } \\
\text { on } \\
\text { PDA }\end{array}$} \\
\hline & & Lamp & Bed & Floor & Walls & Trolley & $\begin{array}{c}\text { Anesthesia } \\
\text { Machine }\end{array}$ & & & \\
\hline 1 & $\begin{array}{c}\text { General } \\
\text { Hospital }\end{array}$ & -- & -- & + & + & -- & -- & + & + & -- \\
\hline 2 & $\begin{array}{c}\text { Children and } \\
\text { Maternity } \\
\text { Home }\end{array}$ & -- & -- & -- & + & -- & -- & + & -- & -- \\
\hline 3 & Eye Care & -- & -- & -- & -- & -- & -- & -- & -- & -- \\
\hline 4 & ENT & -- & -- & -- & -- & -- & -- & -- & -- & -- \\
\hline 5 & $\begin{array}{l}\text { Dental } \\
\text { Clinics } \\
\end{array}$ & -- & -- & + & + & -- & -- & + & + & -- \\
\hline 6 & Skin Care & -- & -- & -- & -- & -- & -- & -- & -- & -- \\
\hline 7 & Cardiac Care & -- & -- & -- & -- & -- & -- & -- & -- & -- \\
\hline 8 & Orthopedic & -- & -- & + & + & -- & -- & + & + & -- \\
\hline 9 & Gynaec Care & -- & -- & + & + & -- & -- & + & -- & -- \\
\hline
\end{tabular}

Fig.1 RCMM broth before and after Incubation RCMM broth turns Black due to growth of Clostridium spp.

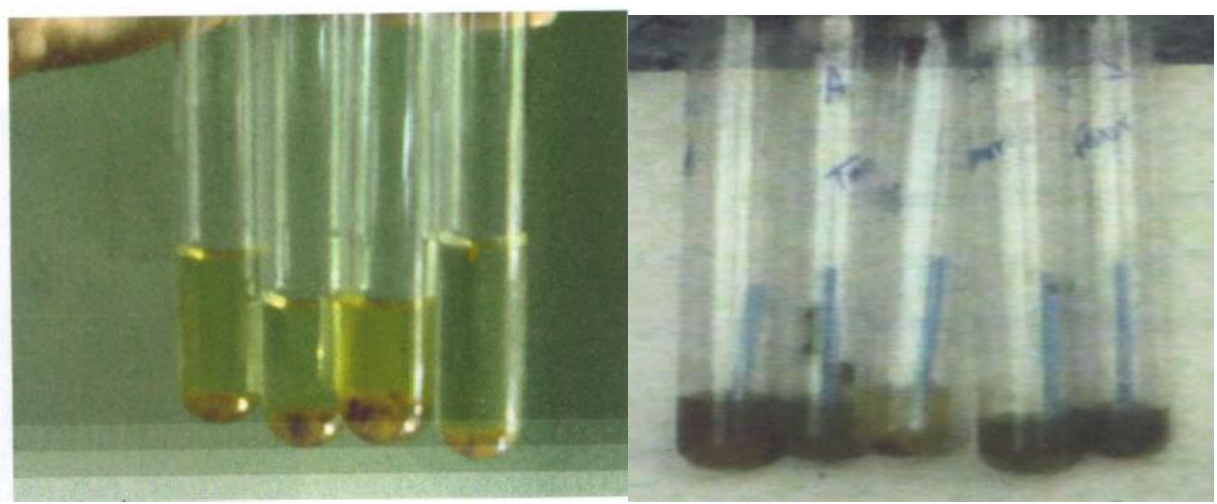

Fig.2 Mixed Type of Culture on CLED agar

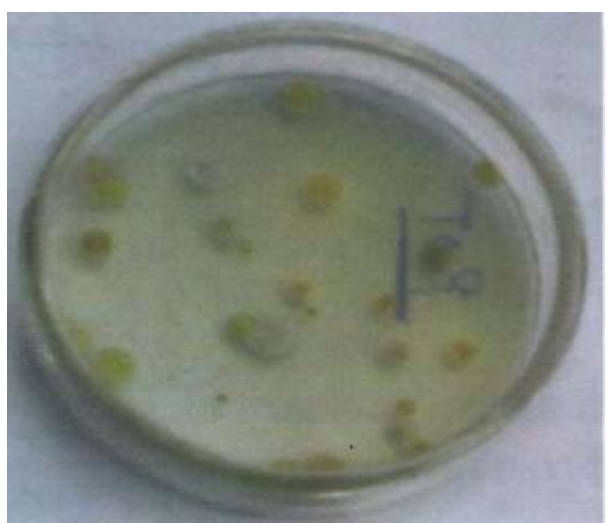


Fig.3 IMViC Test results for S.aureus

Biochemical Tests for Isolated colonies :-

\begin{tabular}{|l|l|c|c|c|c|}
\hline Sr.No. & Name of Organism & Indole & MR & VP & Citrate \\
\hline 1. & S. aureus & - & - & + & + \\
\hline 2. & P. aeruginosa & - & - & - & - \\
\hline
\end{tabular}

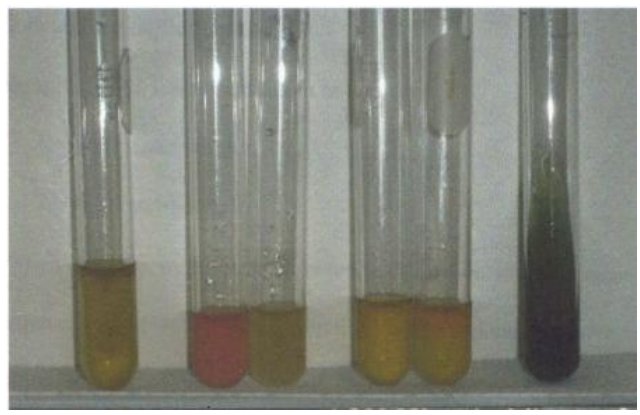

Hospital Environment is always laden with various microorganisms which may cause infectious diseases (WHO; 2009).The Present study includes the samples from 9 hospital operation theaters of Wardha city. The sampling of Operation Theater was carried using open plate method and swab sampling technique. Samples were taken both before and after the sterilization of Operation Theater. The bacterial pathogens were isolated comprising of Staphylococcus aureus and coagulase negative Staphylococci spp., had the highest percentage of occurrence in air samples while in surface samples Pseudomonas spp. showed highest percentage of occurrence.

The study indicates the presence of various species of microorganisms in operation theaters before the sterilization has been done. It truly emphasizes on the absolute sterilization is required in the operation theater for the prevention of nosocomial infections. The research highly recommends not only the methods like Fumigation but if possible also use of newer cleaners such as Bacillocidrasant and Vikron should be used for the absolute removal of the infectious microorganisms (Patwardhan, et al., 2011).

In conclusion, there is need of the day and mandatory to maintain the operation theaters clean and sterile to avoid the post operative infections. Precautionary measures along with proper use of fumigation and cleaners can make this possible.

\section{References}

Bacterial contamination in operating theatres of district hospital budgam in kashmir division singh K, dar F.A., Kishor, K., Department of microbiology, Sri guru Ram Rai institute of technology and science.

Boyce, J.M., Pittet, D. "Guideline for hand hygiene in health-care settings. Recommendations of the healthcare infection control practices advisory committee and the HICPAC/SHEA/APIC/IDSA hand hygiene task force," Morbidity and Mortality Weekly Report, vol. 23, no. 12. 
David, J., Weber, M.D. M.P.H., William, A., Rutala, Ph.D. M.P.H., Dharan, S., Pittet, D. 2002. Environmental control in operating theatres, Hosp Infect., vol. 51(2): pp. 79- 84.

Ens, S., Yef, S.AI. Shalchi, Sabbar, M. 2009. "Microbial Contamination in the operating theater: A study in Hospital in a Baghdad, Eastern Mediterrnean Health J., Vol 15, No.1.

Ensayel, S., Al-Shalchi, S., Sabbar, M. 2009. Microbial contamination in the operating theatre: a study in a hospital in Baghdad, Eastern Mediterranean Health J., vol 15, pp 219-223.

Feather, A.S.P., Stone, A., Wessier, K.A., Boursicot, C., Pratt. 2000. "Now please wash your hands': the hand washing behaviour of final MBBS candidates," J. Hospital Infect., vol. 45, no.pp. 62-64.

Guideline for Disinfection and Sterilization in Healthcare Facilities. 2008. William A. Rutala, Ph.D., M.P.H.1,2, David J. Weber, M.D., M.P.H.1,2, and the Healthcare Infection Control.

Gunasekara, T.D.C.P., Kudavidanage, B.P., Peelawattage, M.K., Meedin, F., Guruge, L.D., Nanayakkara, G., Nanayakkara, M., Fernando, S.S.N. 2009. Bacterial contamination of anaesthetsts hands, personal mobile phones and wrist watches used during theatre sessions. Sri Lankan J. Anaesthesiol., 17(1): 11-15.

Hospital environment Journal. 01' Microbial world) (2) pt I) 1-1)4. Infection Control and Hospital Epidemiology.
Javed, I., Hafeez, R., Zubair, M., Anwar, M.S., Husnain, S. 2008. Microbiological surveillance of operation theatres and ICUs of a tertiary hospital, Lahore Biomedica.

Larson, E.A. 1988. Cause link between hand washing and risk of infection? Examination of the evidence. Infect. Control Hosp. Epidemiol., 9: 28-36.

Lowbury, E.J.L.D.M., Lilly, H.A. 1996. "Contamination of Operation theater air With ,CI tetani." British Medical Journal 1334-Non 29. Clin. Pathol.

Nanoty, V.D.M., Musaddiq, N.A., Aha1e. 2003. Microbiological Studies on air in Hospital environment. J. Microbial. World, 5(2) pp 91-94.

Patwardhan, Narendra, Uday Kelkar. 2011. "Disinfection, sterilization and operation theater guidelines for dermatosurgical practitioners in India." Indian J. Dermatol., Venereol., Leprol., 77(1): 83pp. S3-S40.

Shooter, R.A., Williams, R.E.O. 1996. Prevention of infection in operating theaters. J. Clin. Pathol., pp 14-15.

World Health Organization. 2001. WHO Global Strategy for Containment of Antimicrobial Resistance. WHO/CDS/CSR/DRS/2001.2.

World Health Organization. 2009. WHO Guidelines on Hand Hygiene in Health Care: First global safety challenge: clean care is safe care.

World Health Organization. Prevention of hospital acquired infections. A practical guide. Edited by Ducell, G, FabryJ, Nicoll L.

\section{How to cite this article:}

Abhishek K. Mishra and Vijay S. Wadhai. 2016. Sterility Testing of Operation Theatres in Hospitals. Int.J.Curr.Microbiol.App.Sci.5(5): 440-447. doi: http://dx.doi.org/10.20546/ijcmas.2016.505.046 